\title{
Formation and Functioning of the Communicative Space of the Modern Megapolis (On the Example of the Youth Slang in the City of Kyiv)
}

\section{Prykhodko Iryna Georgiyivna ${ }^{1}$}

Senior Lecturer, Kyiv Medical University, Kyiv, Ukraine.

(date of receiving: June, 2019; date of acceptance: October, 2019)

\begin{abstract}
One of the most active and influential elements in the linguistic landscape of the metropolis is youth slang. This sociolect makes a significant contribution to the formation of the communicative space of the capital. By the example of a lively speech of young Kiev city dwellers in situations of everyday communication the author made an attempt to show how the speech behavior of the youth contributes to the expansion of the range of actual communicative situations and the popularization of slang vocabulary (which is characterized by vivid emotionality and subjective evaluation). The analysis revealed that as a result of the increase in the number of information flows and the role of mass communication (the Internet, social networks, television, radio, the press), the scope of youth slang functioning is expanded and its written form is fixed.
\end{abstract}

Keywords: Sociolect, Youth Slang, Language of the City, Urban Communications.

1. E-mail: rialk21@gmail.com 


\title{
Формирование и функционирование коммуникативного пространства современного мегаполиса (на примере молодёжного сленга г. Киева)
}

\author{
Приходько Ирина Георгиевна ${ }^{1}$ \\ Старший преподаватель, Киевский медицинский университет, \\ Киев, Украина. \\ (дата получения: июнь 2019 г.; дата принятия: октябрь 2019 г.)
}

\begin{abstract}
Аннотация
В настоящее время одним из самых активных и влиятельных элементов языкового ландшафта мегаполиса является молодёжный сленг. Этот социолект вносит существенный вклад в формирование коммуникативного пространства столицы.

На примере живой речи молодых киевлян в ситуациях бытового общения автором была предпринята попытка показать, как речевое поведение молодёжи способствует расширению круга актуальных коммуникативных ситуаций и популяризации сленговой лексики, для которой характерны яркая эмоциональность и субъективная оценка.

Благодаря распространению, доступности и массовости различных гаджетов (планшет, IPad, смартфон), наращиванию возможностей интерактивного общения в общественных местах коммуникация перемещается из приватной зоны в публичную и личная информация становится достоянием широкого круга людей. В результате увеличения числа информационных потоков и роли массовой коммуникации (интернета, социальных сетей, телевидения, радио, прессы) расширяется сфера функционирования молодежного сленга и фиксируется его письменная форма.
\end{abstract}

Ключевые слова: Социолект, Молодёжный Сленг, Язык Города, Городская Коммуникация.

1. E-mail: rialk21@gmail.com 


\section{Введение}

Как известно, значительные социальные, экономические и политические преобразования в жизни общества, вызванные процессом его демократизации, свободой слова и отменой цензуры, обусловливают существенные изменения и в языковом узусе. Авторитетные лингвисты среди актуальных процессов, которые происходят в языке, называют «неумеренную демократизацию языка - его люмпенизацию» (Скляревская 2001. 186), «активизацию разговорной речи, расширение сфер ее функционирования» (Елистратов 2007. 663), «активное взаимодействие литературного языка с просторечием и различными жаргонами» (Валгина 2001), «заимствование языковых элементов (и коммуникативных навыков) из социальных и профессиональных жаргонов и их переход в литературный язык (публичную сферу общения) (Какорина 2003. 251)».

На современном этапе одной из самых ярких и значимых тенденций развития языка считается масштабное продвижение субстандартной лексики с периферии языковой системы в другие области национального языка, более близкие литературному стандарту. Ученые справедливо отмечают, что «...практически во всех европейских языках экспансия жаргона стала реальным фактом, вызывающим тревогу у блюстителей чистоты речи и попытки по-разному оценить и объективно описать эти явления. В каждой стране такая экспансия жаргона имеет свою специфику» (Вальтер, Мокиенко, Никитина 2005.3). Н.С. Валгина обращает внимание на появление «новых центров экспансии - низовой городской культуры, молодежной контркультуры и уголовной субкультуры» (Валгина 2001). В результате целый пласт некодифицированной лексики, ранее использовавшейся при общении только членами социально ограниченных групп, вышел за рамки привычного употребления и хлынул в речь самых широких слоев населения. Сленговые слова и выражения стали активно в проникать во многие сферы общественной 
жизни (публицистику, политические дебаты, средства массовой информации, литературу), а их отдельные элементы фиксироваться в толковых словарях.

Закономерно, что возрос интерес к проблемам живой русской речи и её стали активно изучать в рамках проблем социальной и функциональной дифференциации языка, при анализе активных процессов в языке массовой коммуникации и в контексте языка города

В данной статье на примере молодёжного сленга г. Киева показано как усложняется городская вербальная коммуникация в результате развития технических средств и информационных технологий, появляются новые возможности и каналы общения, а также происходит фиксация сленговой лексики в письменной форме.

\section{Основная часть}

Как справедливо отметила проф. Л.А. Кудрявцева, на протяжении многих лет занимающаяся изучением киевского городского просторечия, «наблюдения над живой речью горожан дают более достоверное представление о языковой ситуации в городе» (Кудрявцева 2001. 7). В полной мере представить этноязыковой ландшафт полилингвокультурного города, по мнению Е.Н. Степанова, позволит методика комплексного исследования феномена разговорной городской речи (Степанов 2013. 9). В процессе городской коммуникации пересекаются и взаимодействуют различные социальные слои населения, разговорная речь которых формирует языковой ландшафт современного большого города. В нём представлены разнообразные социальные диалекты: общий сленг, профессиональные и корпоративные сленги и жаргоны (молодежный, военный, армейский, медицинский, компьютерный, музыкальный, наркоманов, рокеров, панков, хиппи, футбольных фанатов и т. д.), арго преступного мира и др. На современном этапе именно молодёжный сленг является одной из самых активных и 
влиятельных в языковом плане стихий и вносит существенный вклад в формирование коммуникативного пространства мегаполиса.

Как компонент городского просторечия молодёжный сленг находится вне литературного стандарта; используется при неофициальном, непринуждённом общении со своими ровесниками; существует преимущественно в устной форме; характеризуется ярко выраженной эмоциональной экспрессивностью с элементом субъективной оценки (достаточно резкой); отражает ситуации повседневной жизни.

На Украине носители молодёжного сленга (молодые люди в возрасте от 15 до 30 лет) по данным переписи 2001 г. составляют почти 24 \% горожан (более детально с демографическим составом населения можно ознакомиться на сайте 2001.ukrcensus.gov.ua).

Разнообразен и их социальный статус: учащаяся молодёжь (школьники старших классов, студенты высших и средних учебных заведений), рабочая молодёжь, молодая техническая и гуманитарная интеллигенция, солдаты и матросы срочной службы, члены неформальных (панки, хиппи, рэперы и др.) и досуговых (футбольные фанаты, толкиенисты и др.) объединений. Это наиболее деятельная и энергичная часть общества, которая открыта всему новому, не боится экспериментировать и вносить инновации во все сферы своей жизни, а в некоторых случаях даже специально стремится к эпатажу. По своей природе молодёжный сленг является наиболее динамичной системой из всех прочих социальных диалектов, наиболее подверженной влиянию моды.

Такое поведение проявляется и в языке: молодежь активно занимается словотворчеством, стремится создать новые оригинальные номинации с ярко выраженной экспрессивностью. Элементы эмоциональности и субъективной оценки (достаточно резкой), присущие лексике молодёжного сленга, выгодно отличают её от литературных слов и способствуют распространению и расширению первоначальной сферы употребления. Со временем часть слов 
молодёжного сленга (например: балдеть, крутой, продвинутый, тусовщиик, тащиться) может даже получить статус общелитературности, что фиксируется в нормативных словарях современного русского литературного языка при помощи помет. Например, в «Толковом словаре русского языка» С.И. Ожегова и Н.Ю. Шведовой (издание РАН 1999) единицы молодежного сленга (балдеть, голубой, дурь, отмочить, продвинутый, съезжать, тусоваться и др.) сопровождаются пометами «прост.» и «разг.». В «Толковом словаре русского языка конца XX в. языковые изменения» под редакцией Г.Н. Скляревской, где зафиксировано около 190 единиц, определяемых нами как принадлежащие к сфере молодежного сленга, эти слова сопровождаются пометой «ж⿻арг.» (байкер, качалка, круто, крутой, тащииться, тусовочный, тусовщек и др.).

Традиционно сфера формирования и распространения молодёжного сленга ограничивается двумя областями: внутригрупповым общением в референтной группе (нормы и ценности которой наиболее значимы для молодежи) и межгрупповой коммуникацией, предполагающей широкий круг коммуникантов. Между тем актуальные дискурсивные практики городской коммуникации предполагают общение людей, принадлежащих к разным социальным и возрастным слоям населения (школьные товарищи, сокурсники, соседи, коллеги по работе, члены досуговых групп и клубов (хобби, спорт, развлечения т. д.)). Молодёжный сленг в речи горожан можно услышать в разнообразных коммуникативных ситуациях бытового общения вне дома («Транспорт», «Магазин», «Аптека», «Поликлиника», «Очередь» и т. д.). Например, в торговом центре «Самсон» на Подоле женщина-продавец 55 лет (А) предлагает джинсы девушке 30 лет (Б):

Б: Я не люблю с наворотами.

А (показывая другую пару, расшитую блёстками): Bom это вот наворот. $A$ то просто модная тенденция. 
Или на рынке «Оболонь» мужчина-покупатель респектабельного вида 55 лет (А) беседует с женщиной-продавцом 30 лет (Б).

A: Мне вырезки телячьей грамм семьсот!

Б: Здесь больше.

\section{A: Покатит!}

Б: Так покатит, или меньше?

\section{A: Ta покатит!}

В условиях современного мегаполиса бытовое общение способствует расширению сфер функционирования молодёжного сленга за счет городской, семейной и массовой коммуникации.

Посредством внутрисемейной коммуникации осуществляется влияние речи молодого поколения на языковые привычки взрослых, когда в речевой манере старших представителей семьи появляются специфические «следы», унаследованные от детей и внуков: Часов до одиннадиати почти никого не было, а потом вдруг, как говорит мой сын, начался такой движняк. (говорит женщина 42-х лет, общаясь с подругой). Как ты там любишь повторять? Cуnер-nуnер волкодав? (спрашивает мужчина 64 лет у внука). Что же ты у своего продвинутого Тараса не спросил? Тут он для тебе не авторитет? (спрашивает женщина 47 лет у сына-подростка.).

Существенные изменения в сфере городской коммуникации произошли с распространением Интернета, стремительным развитием в области компьютерных и электронных технологий, спутниковой связи, а также глобализационными процессами в обществе. Разнообразие индивидуальных средств связи (планшет, IPad, айфон, МP3-плейер, электронная книга, смартфон), их общедоступность и массовое распространение среди населения приводит к тому, что у современных горожан формируется зависимость от гаджетов, так называемый «гаджетинг» (Препотенская 2016. 59). Развитие мобильной связи и создание специальных программ для смартфонов и 
планшетов, обеспечивающих передачу текстовых (чат), видео и аудиосообщений при помощи IP-телефонии (Skype) и WiFi (Viber), позволяет вести приватные разговоры в общественных местах при большом скоплении людей (в транспорте, кафе, торговых центрах, государственных учреждениях и др.). В таких условиях все присутствующие помимо своей воли становятся пассивными участниками коммуникативного акта и знакомятся с особенностями речи говорящего. Коммуникация при помощи sms-сообщений предполагает при минимуме языковых средств передать максимум информации, поэтому в таких сообщениях активно используются сленговые единицы, отличающиеся краткостью и семантической насыщенностью.

Значительная роль в популяризации лексики молодёжного сленга и её дальнейшем распространении принадлежит средствам массовой информации (телевидению, прессе, радио, рекламе и Интернету). Именно прессу, кино, телевидение, радио следует считать основными каналами распространения и популяризации лексики молодежного сленга, т. к. СМИ несут информацию о разнообразных сторонах общественной и культурной жизни. Пресса мгновенно реагирует на все актуальные события в жизни социума, на все изменения человеческой деятельности и отражает их в языке, выступает посредником в миграции слов. Почти во всех материалах, касающихся особенностей образа жизни молодых людей, их интересов, вкусов, увлечений, употребляется сленговая лексика, так как она помогает передать систему мировоззрения, ценностных ориентаций, стереотипов поведения молодежи. Активность употребления единиц молодежного сленга в СМИ зависит от того, на какой круг читателей, слушателей, зрителей рассчитан подготовленный материал - авторы могут использовать как отдельные вкрапления сленговых элементов, так и сплошной сленг.

Использование сленговых слов в средствах массовой информации, ориентированной на самые широкие слои населения, свидетельствует, во- 
первых, о расширении сферы употребления данного сленгизма (как правило, появление сленговой единицы в прессе сигнализирует о широкой известности данного слова и его востребованности), а во-вторых, фиксирует письменную форму.

Лексика молодёжного сленга часто употребляется в тематических статьях, цель которых - правдиво отобразить определённый сегмент действительности, связанный с образом жизни молодых людей, например: Так что решайся, подумай один раз хорошо, и, решившись, больще не задумывайся- полный оттяг гарантирован. Для особо крутых возможно предоставление поездок на кавказские курорты, где тусуются самые навороченные сноубордеры России и других стран бвышего «совка». [Х3М, № 2(15), 2011]. Музыкальносидюшная контора «Вули-Булли» не перестает нас радовать свежаками для ушей и хорошего настроения. Три очередные плиты порадовали нас и очень скоро порадуют вас. [Х3М, № 10, 2000].

Часто молодёжный сленг используется в статьях, авторы которых имитируют стиль общения определенного круга молодежи, например: Продолжаем базар в русле Ди-джейских понятий и далее имеем телегу о том, какие бывают виниль. Для тех, кто вообще не вдупляет зачем это, объясняю: это типа спеиэффекты, для тех, кто шарит поясню: хочешь спрейчевать- пробивай у знакомых, где можно выкупить эту иенную пластинку [Х3М, № 2(15), 2015].

Современные СМИ выполняют не только информационную функцию, для них характерно стремление воздействовать на читателя / слушателя / зрителя, подавая информацию в наиболее образной форме. Поскольку для масс-медиа характерно стремление ориентироваться на разговорную речь обычного носителя языка, поэтому активно используются сленговые слова с ярко выраженной эмоционально-экспрессивной окраской: Кто из артистов честно отслужил в армии, а кто предпочел откосить? [«Отдохни», № 9, 2015]; $A$ 
поскольку работать без программистов было невозможно, я тоже подключился к «Александру». В конще возникла страшная запарка, каждый человек на счету. [«Gameplay», март, 2015]; Все начиналось с непоняток. Желание с нашей стороны и приглашение с российской стороны от B-Pеорlе было, но не было самого главного - финансы пели романсы и упорно не хотели наполнять карманы... За последние годы поклонники этого стиля получили возможность классно отрываться на танциполах [Х3М, № 2, 2013].

Очень часто молодежные сленгизмы в СМИ используются с целью привлечения внимания аудитории. В таких случаях употребление сленговых слов свидетельствует о том, что автор и читатель принадлежат к одному кругу, их объединяют общие интересы и увлечения, например: Обращаюсь сейчас к тебе, да, к тебе, читатель этой статьи. Ты, чувак, один из последних, кто до сих пор ничего не сльшал об этом, на первый взгляд слегка мажорном, но, в сущности, еще не полностью обвешанном цепями обладателе всяческих музыкальных премий, не говоря уже о прекрасном, почти нулевом Бентли. Средства массовой информаџии подсадили тебя на Нелли на уровне подсознания [Х3М, № 9, 2012].

В настоящее время в средствах массовой информации молодёжный сленг присутствует не только в речи журналистов, проблемных статьях, мнениях экспертов и аналитиков, но и в так называемых «вторичных» текстах интервью, в рубрике ответов и вопросов, переписке с читателями, в журналистских наблюдениях, а также в статьях развлекательного характера анекдотах, гороскопах. Например, в интервью Валентина Семенюк отвечает корреспонденту: Семенюк никогда не была тормозом, Семенюк показала всем, что такое инвентаризация, те сбережения, которые возвращаются, возвращ,аются и благодаря Семенюк (Forum, 06.02.2008); врач-нарколог отвечает на вопросы читателей в рубрике «Вопросы доктору»: Кайф подростка от пива и балдёэс от травки - это кайф на самом краю 
наркотической пропасти. (КП, 29.09.05); анонс комедии «Крутая Джорджия»: Признавшая поражение в борьбе с дочкой-оторвой мать привозит Рейчел на перевоспитание к суровой бабушке Джорджии (от которой когда-то сама сбежала) (Сегодня, 09.02.2008); анонс фильма «Вечеринка на Ибице»: А она иелуется со звездным ди-джеем и собирается с ним на Ибииу-зажигать на самой крутой вечеринке». (КП, 09.02.2008); юмор: «Раньше пацаны ставили на бабки конкретно. А сейчас это стыдливо называют кредитом» (КП, 09.02.2008).

Употребление сленгизма в анекдотах и городском фольклоре является свидетельством его освоения основной массой населения, т. к. здесь начинается игра со словом, которая предполагает прекрасное знание языкового материала, всех смысловых нюансов и оттенков. Языковая игра может базироваться как на народной смеховой культуре (балагурстве), так и на содержательной и формальной многоплановости (острословии). Многие анекдоты построены на каламбурном обыгрывании омонимии сленгизмов и слов общенародного языка, что создает комический эффект, например: «Блин!» - сказал слон, наступив на колобка; Последние слова свиньи на мясокомбинате: «Меня колбасит»; - Как получилось, что вы сбили старушку? - Еду, вдруг бабка из-за угла. Паианы кричат: «Тормози!». Ну, я и стормозил.

В данных случаях языковая игра не ограничивается только каламбурным отнесением одного слова к двум разным смысловым планам, что обеспечивает одновременную реализацию разных значений слов (лит. блин 'тонкая лепешка из жидкого теста, испеченная на сковородке' и мол. блин 'эмоциональное восклицание, которое может выражать досаду, удивление, гнев, страх, разочарование'; прост. колбасить 'делать колбасу' и мол. колбасить 'плохо себя чувствовать'; лит. тормозить 'замедлять или останавливать движение тормозом' и мол. стормозить 'вовремя не среагировать, не сообразить'). 
Каламбурное сближение происходит на фоне конкретной ситуации. Тем самым, говорящие, прибегая к языковой игре, актуализируют внеязыковой фон, сопутствующий ситуации речи, включая его в акт коммуникации.

В XXI в. возможности современных СМИ влиять на читателей и слушателей возросли многократно благодаря увеличению числа информационных потоков и появлению новых мультимедийных технологий. Так, широко распространяются возможности интерактивного общения с радио- и телеаудиторией, когда любой зритель или слушатель может дозвониться на радио или в телевизионную студию, задать вопрос, принять участие в обсуждении и тем самым быть услышанным многомиллионной аудиторией. Приобретают популярность онлайн-конференции, репортажи и трансляции с мест катастроф, стихийных бедствий, спортивных и развлекательных мероприятий, которые предоставляют возможность переживать публичные событие онлайн, в режиме реального времени и тем самым ощущать свою причастность к событию и вовлеченность в него. В современных реалиях любой житель мегаполиса может стать участником съемки телепередачи, реалити-шоу, дать интервью, принять участие в соцопросе или экзитполе. Все эти теле- и радиожанры ориентированы на живое общение, спонтанную речь, которая идёт в эфир без цензуры и передаёт особенности речи горожан: «Теперь вы знаете остров, где можно классно розкумариться!» [принять наркотик, испытать состояние наркотической эйфории] (комментарий ведущего к песне); «А у меня есть информаџия о том, как богатые люди делают покупки и как они покупаются на скидки» (речь диджея); «Вот, казалось бы, детский анекдот, а надо ж въехать!» (из беседы ди-джея с радиослушателями).

Речь различных молодёжных групп (с соответствующими языковыми особенностями) в разнообразных коммуникативных ситуациях широко представлена в теле и радиопрограммах (репортажах, круглых столах и т. п.), 
где участниками коммуникации выступают не только журналисты, но и представители самых разных профессий, социального статуса, уровня образования. Особенно плодотворны в плане популяризации молодёжного сленга ток-шоу, реалити-шоу, где живая речь участников практически не подвергается редактированию. Следуя специфике жанра, как правило, развлекательного, сленг употребляют как герои передач, так и журналисты: Дорогие телезрители! Хочу заметить, что тот, с кем упльввает прекрасная Елена на остров Цитеру не дед Пихто и не конь в пальто, а Парис, сын иуаря Приама (А. Вартгафтик комментирует сюжет оперетты Оффенбаха; РТР, программа «Камертон», 27.11.05).

Сейчас для того, чтобы стать героем видеосюжета не обязательно принимать участие в теле или радиопрограммах. Технические возможности мобильных телефонов и планшетов в настоящее время позволяют любому человеку самому снять видеосюжет, прокомментировать его или сопроводить печатным текстом и выложить в общий доступ на Youtube, в Instagram или любой другой ресурс. При этом человек сам занимается своей презентацией, решает, что и как он скажет аудитории.

Мощным и агрессивным источником распространения МС является реклама, которая в прагматических целях (манипулирования сознанием, психологического программирования) использует экспрессивный и семантический потенциал сленговой лексики: «Таскома. Без облома!» (Реклама посуды марки «Таscoma» в передаче «Вкусно с Борисом Бурдой»); «Хакнуть по-русски! Новый год для ламера» (Анонс журнала «Internet.com»; реклама в метро); «„Репарил”. Зашибись! - Допомагає!» (Реклама геля от ушибов). Как правило, это реклама товаров «модного» образа жизни и атрибутов сферы развлечений (мобильной связи, слабоалкогольных напитков, орешков, батончиков) и она адресована основному потребителю этой продукции молодёжи: «Теперь «Беz тормозов» - газета не только об автомобилях. С 2003 
года 2 раза в месяи - всё о самых улётных людях, событиях, фактах, приколах, заморочках! Экстремальное чтиво: как получать удовольствие от жизни, крутые способы заработка, убойные откровения звёзд. ЖИЗНЬ БЕЗ БАШНИ, ЖИЗНЬ БЕЗ ТОРМОЗОВ! В 2 раза больше информаџии! Не опоздай! Живи без тормозов!» (Реклама в газете «SPEEDДекамерон», № 2, 2003). Такая реклама является наиболее частотной на ТВ и поневоле запоминается и другими социальными слоями населения, не имеющими отношения к сфере сленгового словоупотребления, в том числе, людьми старшего возраста. Таким образом, происходит приобщение этих социальных групп к восприятию и употреблению разнообразной сленговой лексики.

С развитием электронных средств массовой информации употребление молодежных сленгизмов перестало ограничиваться исключительно сферой устной речи. Интернет предоставил возможности общения на виртуальных площадках: на страницах разного рода тематических форумов, сайтов, социальных сетей, электронных СМИ. Например, в настоящее время сообщества https://www.liveinternet.ru, https://www.livejournal.com (живой журнал, жж), http://www.diary.ru (дневники) объединяют десятки тысяч пользователей.

Значительная роль в распространении молодёжного сленга принадлежит блогерам - людям, которые ведут электронные дневники, онлайн-дневники и на их страницах на регулярной основе размещают записи, содержание тексты, изображения и видео. Блоги разнообразны по своей направленности и ориентированы разную целевую аудиторию: среди них есть простые дневники для самовыражения, дневники с описанием хобби и увлечений (путешествия, спорт, музыка, быт, дизайн, хенд-мейд, здоровый образ жизни, мода, история, фанатская субкультура и т. д.), дневники общественной направленности (политика) и дневники, направленные на продвижение товаров и услуг. Блог соединяет в себе мультимедийные возможности СМИ и непосредственность живого общения. Он предоставляет читателям с одной стороны получение 
информации и чтение-развлечение, с другой - отслеживает реакцию публики на те или иные события политической, общественной и культурной жизни страны, с третьей - даёт возможность расширить круг общения, принимать участие в дискуссиях и обсуждениях, делиться своими мыслями и излагать «наболевшее», с четвёртой - анонимность пользователей располагает к более неформальному контакту и позволяет обсуждать самые откровенные темы, что часто затруднительно при непосредственном общении.

Общение в чатах, электронные дневники, комментарии к новостям и статьям, отзывы пользователей разных товаров, авторские блоги - все эти виды коммуникативной активности ориентированы на спонтанную речь, содержат большую квоту молодёжного сленга и предполагают письменное оформление. Приведём примеры (сохранена авторская орфография и пунктуация): «У меня вот тут нарисовался было свободный часок, я $и$ пробежалась взглядом по дневникам, меня интересующим... Я иногда обалдеваю, до чего доходит скупость людей. Сейчас о конкретном человеке говорю. Мы с ним сотрудничаем уже года три, какой-то период он пытался меня куда-то приглашать, ну, вроде виды имел» (электронный дневник); «Мышка отказываеться пахать. В плане столько я раз жала уже копировать, вставить, копировать, вставить что сейчас она меня просто игнорит. Наверное там есть какое то определенное кол-во подобных операций и больие никак. Уже перезагружалась. Было нормально. Сейчас опять не хочет. Че опять перезагружаться? Может есть другие вариантьл? Я жму вставить, но ничего не происходит. Отбой. Всем спасибо:) Мне в асе уже рассказали:) Все в порядке уже» (форум компьютерщиков); «Настроение просто суперовое )) Сам не знаю, что случилось, но не могу не вынесты боооооольшущую благодарность Acris, Anya_Lucky, Humble \& Ver, u, 8 меньшей степени, Sheеa \& Mickele за то, что они, сами того не ведая, вытащили меня из депресняка )) Хадю и ульбаюсь ;) ;)» (авторская запись в 
Facebook); «Мило посидели, человек в реале оказался ещё более прикольный, чем в интернете:))» (комментарий в чужом дневнике); «Телефон как для девушки прикольный, но вообще попса. Щас юзаю свой старый SIEMENS, так он ито круче!» (отзыв пользователя мобильного телефона).

Раньше молодежные сленгизмы использовались при таком характерном для молодежи способе общения, как записки школьников (студентов) на уроках (лекциях). В современных условиях этот вид коммуникации трансформировался в sms-переписку и общение в закрытых чатах, но попрежнему практически недоступен для исследователя, так как содержат сведения интимного характера, не предназначенные для оглашения. С другой стороны, современные технические возможности позволяют делать скриншоты такой переписки и выкладывать её в общий доступ. Как правило, это происходит в случае возникновения конфликтной ситуации между коммуникантами, когда одна из сторон придаёт огласке сугубо личную информацию.

Таким образом, расширение сферы употребления молодежных сленгизмов происходит не только в плане увеличения числа коммуникативных ситуаций и информационных потоков, но и в плане перехода их из устной речи в письменную.

\section{Заключение}

Анализ живой речи киевской молодёжи показал, что в настоящее время в результате активного использования молодежных сленгизмов вне традиционного употребления в пределах устного внутригруппового и межгруппового общения происходит расширение коммуникативных сфер их функционирования за счет семейной, городской и массовой коммуникации.

Благородя внутрисемейной коммуникации элементы молодежного сленга попадают в речь представителей старшего поколения. 
Общедоступность и разнообразие индивидуальных средств связи способствуют увеличению числа информационных потоков, в результате чего происходит стирание пространственных, временных и социальных барьеров и в публичное пространство городской коммуникации переносятся ситуации «Деловой разговор по телефону» и «Разговор по телефону на личные темы».

Основным каналом распространения и популяризации сленговой лексики являются СМИ (как издания общего информационного профиля, так специализированные - ориентированные на молодежь и развлекательные) и Интернет. Коммуникация на страницах электронных СМИ, форумов, сайтов, социальных сетей свидетельствуют о расширении сферы употребления молодежных сленгизмов и массовом распространении их письменной формы.

\section{Литература}

1- Валгина Н.С. (2001) Активные процессы в современном русском языке: Учебное пособие. Москва, Изд-во «Логос». [Электронный источник]. - Режим доступа: http://www.hi-edu.ru/e-books/xbook050/01/

2- Вальтер Х., Мокиенко В.М., Никитина Т.Г. (2005) Толковый словарь русского школьного и студенческого жаргона: около 5000 слов и выражений. Москва, Изд-ва «Астрель», «АТС», «Транзиткнига».

3- Елистратов В.С. (2007) Толковый словарь русского сленга. - Москва, Изд-во «АСТ-ПРЕСС КНИГА».

4- Какорина Е.В. (2003) Сфера массовой коммуникации: отражение сочиальной дифференцированности языка в текстах СМИ // Современный русский язык: Социальная и функциональная дифференциация / Рос. академия наук. Ин-т русского языка им. В.В. Виноградова. - Москва, Изд-во «Языки славянской культуры». С. 241-276.

5- Кудрявцева Л.А. (2001) Русское городское просторечие: Киев - 2000 // Русистика, № 1, с. 4-9.

6- Препотенская М.П. (2016) Коммуникащия в мегаполисе: приватная публичность и публичная приватность // «Урбанистические студии: современное состояние и перспективы развития». Материалы II Всеукраинской научно-практической конференции (г. Днепропетровск, 25 марта 2016 г.). - Днепропетровск, Изд-во «Грани», с. 59-61.). 
7- Скляревская Г.Н. (2000) Слово в меняющемся мире: Русский язык начала XXI столетия: состояние, проблемы, перспективы // Исследования по славянским языкам 2001. 6. Корейская ассоциация славистов. Сеул. С. 177-202.

8- Степанов Е.Н. (2013) Русская городская речь в полилингвокультурном пространстве Одессы: автореф. дис. д. филол. наук, Киев. - 33 с.

\section{Bibliography}

1- Valgina N.S. (2001) Aktivnye processy v sovremennom russkom jazyke: Uchebnoe posobie. Moskva, Izd-vo «Logos». [Jelektronnyj istochnik]. - Rezhim dostupa: http://www.hi-edu.ru/e-books/xbook050/01/

2- Val'ter H., Mokienko V.M., Nikitina T.G. (2005) Tolkovyj slovar' russkogo shkol'nogo i studencheskogo zhargona: okolo 5000 slov $i$ vyrazhenij. Moskva, Izdva «Astrel'», «ATS», «Tranzitkniga».

3- Elistratov V.S. (2007) Tolkovyj slovar' russkogo slenga. - Moskva, Izd-vo «ASTPRESS KNIGA».

4- Kakorina E.V. (2003) Sfera massovoj kommunikacii: otrazhenie social'noj differencirovannosti jazyka v tekstah SMI // Sovremennyj russkij jazyk: Social'naja i funkcional'naja differenciacija / Ros. akademija nauk. In-t russkogo jazyka im. V.V. Vinogradova. - Moskva, Izd-vo «Jazyki slavjanskoj kul'tury». S. 241-276.

5- Kudrjavceva L.A. (2001) Russkoe gorodskoe prostorechie: Kiev - 2000 // Rusistika, № 1, s. 4-9.

6- Prepotenskaja M.P. (2016) Kommunikacija v megapolise: privatnaja publichnost' $i$ publichnaja privatnost' // "Urbanisticheskie studii: sovremennoe sostojanie i perspektivy razvitija». Materialy II Vseukrainskoj nauchno-prakticheskoj konferencii (g. Dnepropetrovsk, 25 marta 2016 g.). - Dnepropetrovsk, Izd-vo «Grani», s. 59-61.).

7- Skljarevskaja G.N. (2000) Slovo v menjajushhemsja mire: Russkij jazyk nachala XXI stoletija: sostojanie, problemy, perspektivy // Issledovanija po slavjanskim jazykam 2001. 6. Korejskaja associacija slavistov. Seul. S. 177-202.

8- Stepanov E.N. (2013) Russkaja gorodskaja rech' $v$ polilingvokul'turnom prostranstve Odessy: avtoref. dis. d. filol. nauk, Kiev. -33 s.

\section{HOW TO CITE THIS ARTICLE}

Приходько И. Г. (2020). Formation and Functioning of the Communicative Space of the Modern Megapolis (On the Example of the Youth Slang in the City of Kyiv). Issledovatel'skiy Zhurnal Russkogo Yazyka I Literatury, 8(1), 157-174.

DOI: $10.29252 /$ iarll.15.157

URL: http://www.journaliarll.ir/index.php/iarll/article/view/114

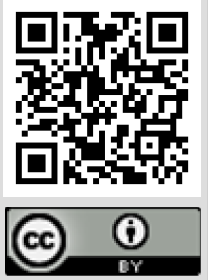




\title{
شكل گيرى و عملكرد فضاى ارتباطى در كلانشهر مدرن
}

(از دريجهُ زبان عاميانه جوانان در كيف)

\author{
ايرينا گئورگيونا بريخود كا' \\ استاديار، دانشگاه ملى تاراس شفِقِنكو كيف، \\ كيف، اوكراين.

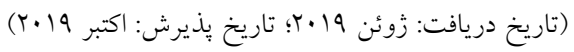

در حال حاضر، يكى از مؤثرترين و تأثير كذارترين عناصر زبانى كلانشهرها، زبـان عاميانسة

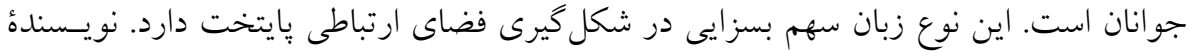

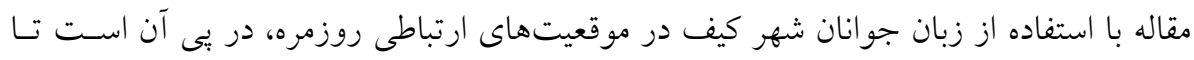

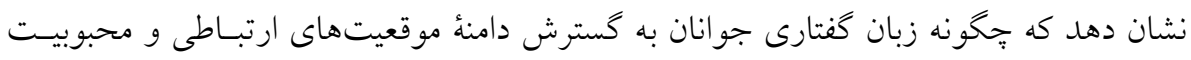

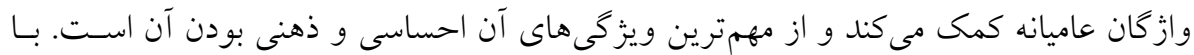

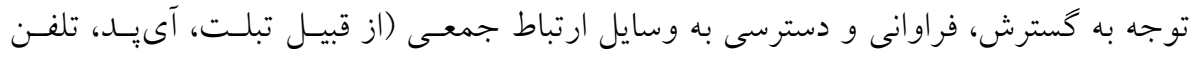

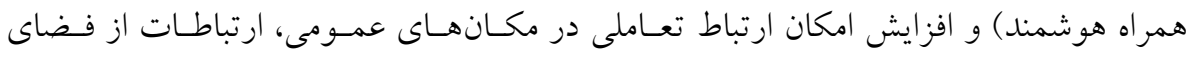

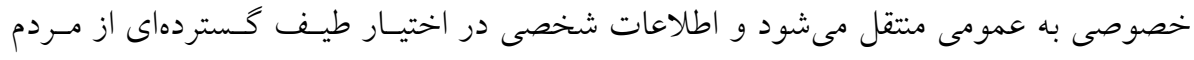

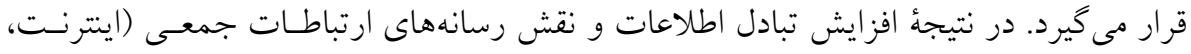

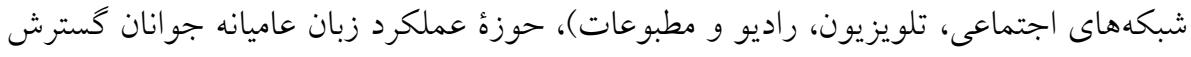

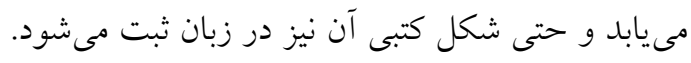

وازگكان كليدى: زبان خاص طبقهاى از اجتماع، زبان عاميانهُ جوانان، زبان شهر، ارتباطات شهرى. 